\title{
A Comparison of Control Design Methods for Philips Glass Furnace using Experimental Data
}

\author{
Magdi S. Mahmoud ${ }^{+}$
}

\begin{abstract}
This paper describes a comparison of control system design to Philips glass furnace. The first stage considers the application of system identification techniques to obtain models using experimental data. Several models were identified, wherein the one picked up for control design has the largest level of fitness. In the second stage a set of improved control methods are implemented to design controllers based on non-adaptive (including LQR, LQGR, $\mathrm{H}_{2}, \mathrm{H}_{\mathrm{oo}}$ ) and adaptive (including MRAC, L1) methods. Simulation studies were performed and evaluated.
\end{abstract}

Keywords- Philips glass furnace, identification, control design, adaptive methods, non-adaptive methods.

\section{Introduction}

A Philips glass furnace considered as a chemical reactor, where the raw materials are burnt in a confined space surrounded by refractory, at high temperatures of 1400 1600 degree $\mathrm{C}$ to produce molten glass, see Fig. 1 . The melting area of a glass furnace consists of a molten glass bath and a combustion chamber. The walls, floor and the roof of the melting area are made up of refractory (which is capable of handling high temperatures). The furnace operation involves combustion, heat transfer, batch melting, glass flow patterns. [1] - [4]. In the literature, there are several methods for identification and/or control of different types of glass furnace [8]-[20]. The combined identification and control design based on empirical data for glass furnace has received little attention.

In this paper, we develop a two-stage approach to the control design of Philips glass furnace. In the first stage, a mathematical model of is identified using empirical data. This model is then fed to the control design pool of methods, which consist of non-adaptive (including LQR, LQGR, $\mathrm{H}_{2}$, $\mathrm{H}_{\mathrm{oo}}$ ) and adaptive (including MRAC, $\mathrm{L}_{1}$ ) methods. By extensive Matlab-based simulation studies, the performance of the design methods is compared and evaluated.

\section{Identification Stage}

Using the DaISy (Database for the Identification of Systems; SISTA's Identification Database), a data set consists of 1247 samples of three inputs and six outputs. The inputs represent the heating and cooling inputs to the furnace and, all the six outputs represent the outputs from temperature sensors in a cross section of the furnace. There are two types of modeling techniques that are

+ Distributed Control Research Lab,

Systems Engineering Department, KFUPM,

P. O. Box 5067, Dhahran 31261, Saudi Arabia

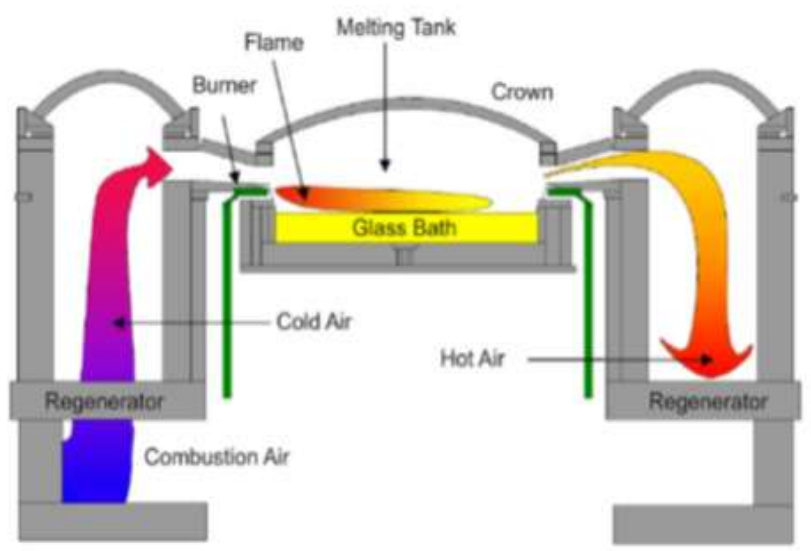

Fig. 1. Schematic of a glass furnace

currently applied for modeling of glass manufacturing processes: Black-box method and First-principles-based method. In the first method, a mathematical model of the process is obtained from the experimental inputoutput data of the process by applying identification techniques. Process identification techniques result in models that allow very fast simulation of process dynamics [2], [3]. In the second method, a mathematical model is derived from basic physical laws utilizing computational fluid dynamics (CFD) techniques. In this paper, we follow the first method using the data in Figs 2-4.

Using parametric identification techniques, we obtain state-space models that represent dynamical models of the glass furnace from the on-line data. The basic state-space model in innovations form can be written as:

$$
\begin{aligned}
x\left(t+T_{s}\right) & =A x(t)+B u(t)+K e(t) \\
y(t) & =C x(t)+D u(t)+e(t)
\end{aligned}
$$

Where $x(t)$ is the state vector, $u(t)$ is the input vector, e $(t)$ is the noise vector and $\mathrm{y}(\mathrm{t})$ is the output vector. In addition, A is the state matrix, B is the input matrix, $\mathrm{C}$ is the output matrix, $\mathrm{D}$ is the feedthrough matrix, and $\mathrm{K}$ is the matrix representing the noise/disturbance characteristics of state space models: Subspace method (N4SID and Prediction Error Method (PEM) [7]. The numerical values of matrices are omitted for space limitation. A comparison between the n4sid model and the pem model obtained using one data set is depicted in Fig. 5, whereas a comparison of the fitness of $\mathrm{n} 4$ sid models and pem models using different sets of data for output $\mathrm{y}_{1}$ is presented in Fig. 6 . 
Proc. of the Fourth Intl. Conf. Advances in Computing, Communication and Information Technology- CCIT 2016

Copyright (C) Institute of Research Engineers and Doctors, USA .All rights reserved.

ISBN: 978-1-63248-092-7 doi: 10.15224/ 978-1-63248-092-7-26
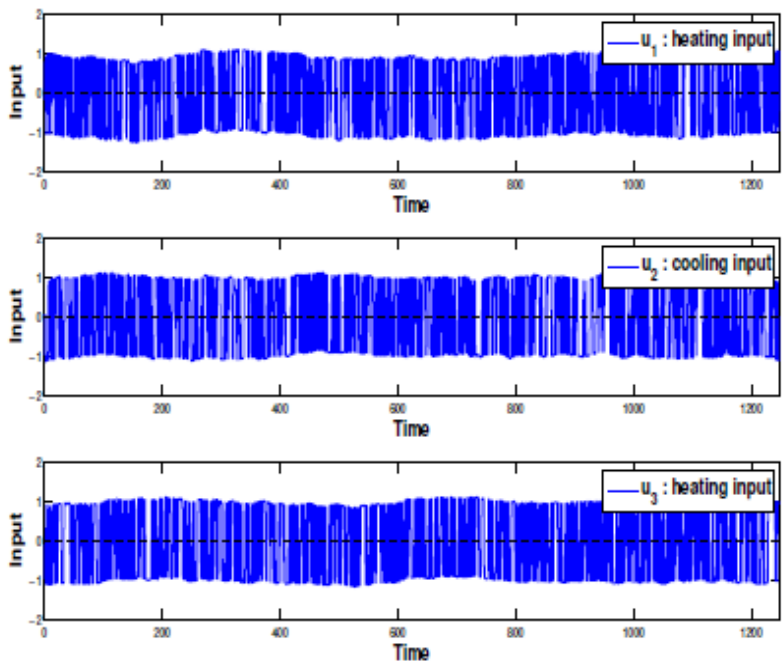

Fig 2. Input data
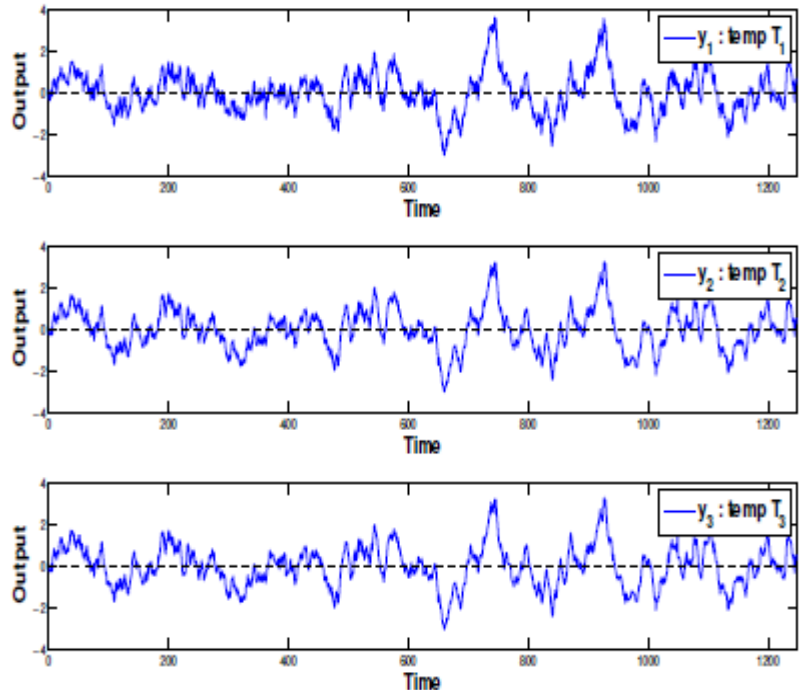

Fig 3. Output data I
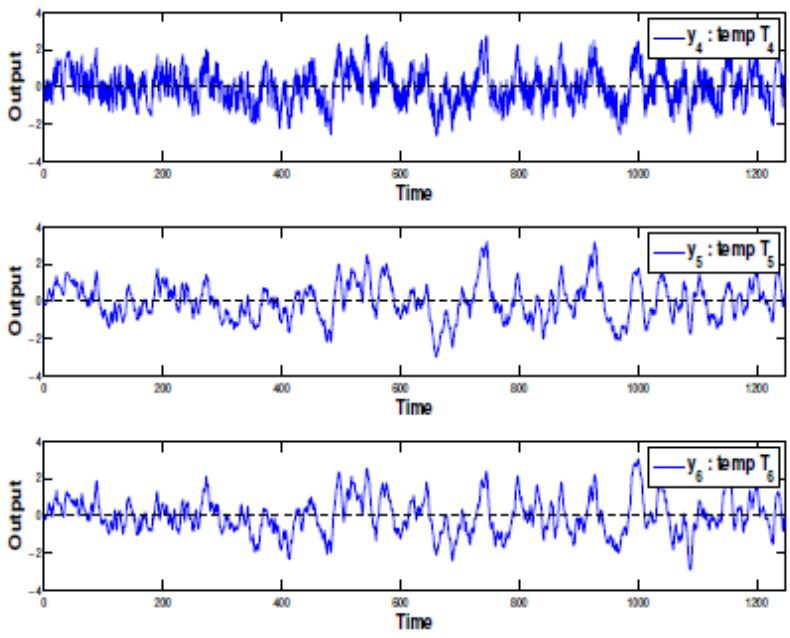

Fig 4. Output data II

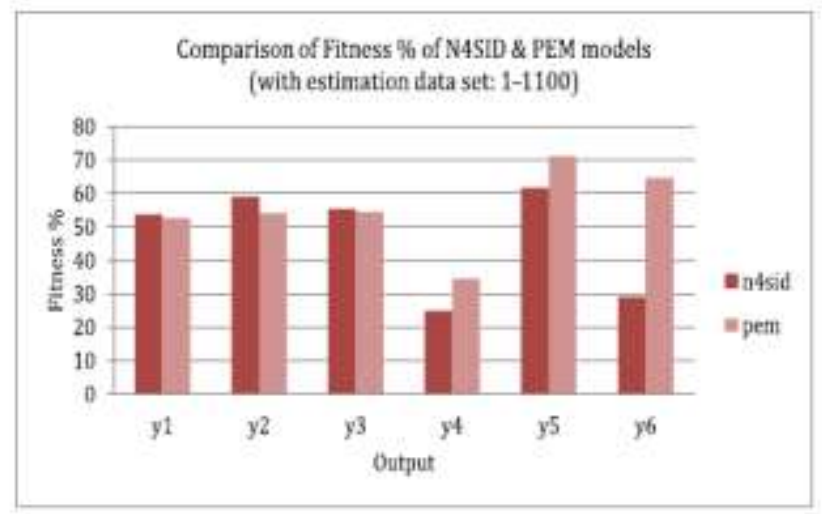

Fig 5. Fitness comparison of $\mathrm{n} 4$ sid model and pem model obtained from the estimation data $1-1100$

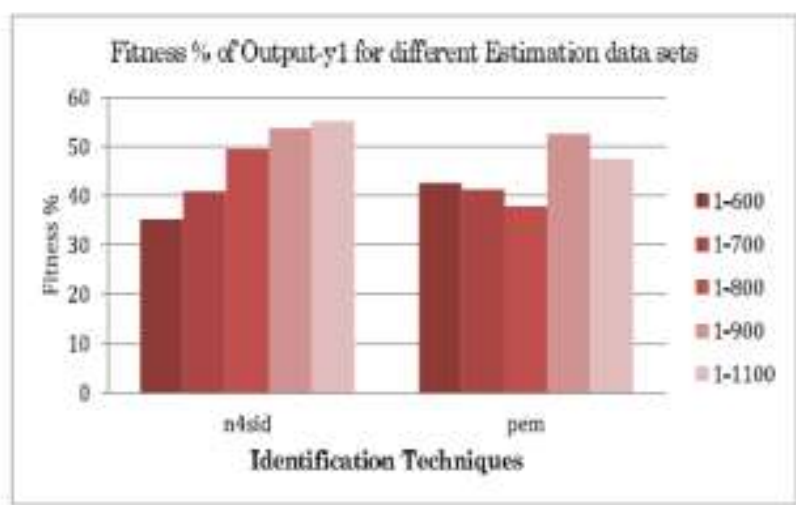

Fig 6. Fitness comparison of different $n 4$ sid models and pem models

\section{Control Design Stage}

The problem now is to determine the controller to be applied to the identified Philips glass furnace model to achieve a desired steady-state temperate profile. The methods of control design considered in the present work is divided into two distinct categories: non-adaptive category including linear-quadratic regulator (LQR), linear-quadratic Gaussian regulator (LQGR), optimal $\mathrm{H}_{2}$ and optimal $\mathrm{H}_{\mathrm{oo}}$ ) and adaptive category including MRAC, L1 methods. The theory of these methods omitted due to space limitations

\section{A. Non-Adaptive Control Design}

In this category of control design methods, we considered

- Linear quadratic regulator (LQR)

- Linear quadratic Gaussian regulator (LQGR)

- $\mathrm{H}_{2}$ and $\mathrm{H}_{\mathrm{oo}}$ Control

In simulation, we used Matlab and Simulink. Optimal and robust controllers are designed for the identified glass furnace model. The output trajectories are shown in Figs $7-$ 10. The following observations are deduced from the simulation results:

- With $\mathrm{H}_{2}$ controller, the overshoot in the output and the settling time are relatively less.

- The output experiences a large overshoot with $\mathrm{H}_{\mathrm{oo}}$ controller.

- The response of LQR and LQGR is exactly similar and is better than the $\mathrm{H}_{\mathrm{oo}}$ controller response.

Among the four non-adaptive controllers, it appears that 
Proc. of the Fourth Intl. Conf. Advances in Computing, Communication and Information Technology- CCIT 2016 Copyright (C) Institute of Research Engineers and Doctors, USA .All rights reserved.

ISBN: 978-1-63248-092-7 doi: 10.15224/ 978-1-63248-092-7-26

$\mathrm{H}_{2}$ controller provides best closed-loop performance for the identified glass furnace model.
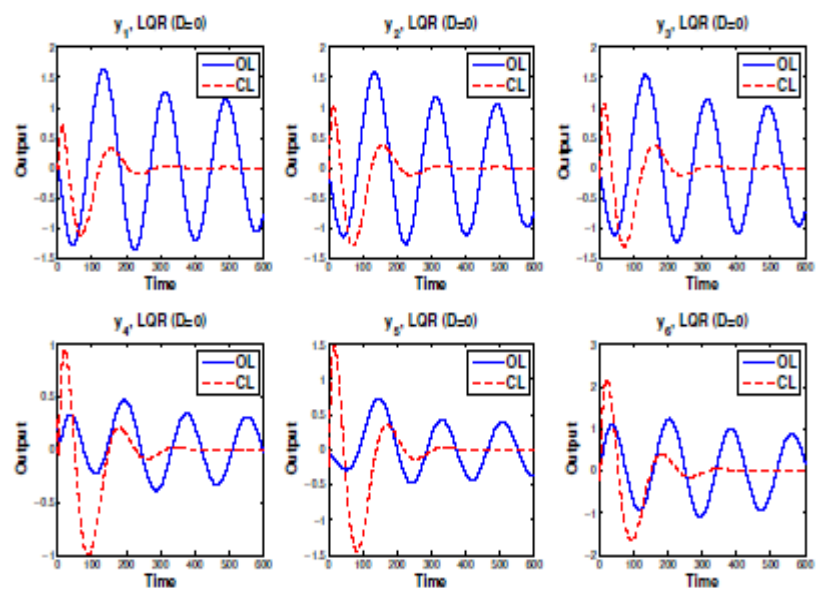

Fig 7. LQR: Output trajectories for open loop and closed-loop systems
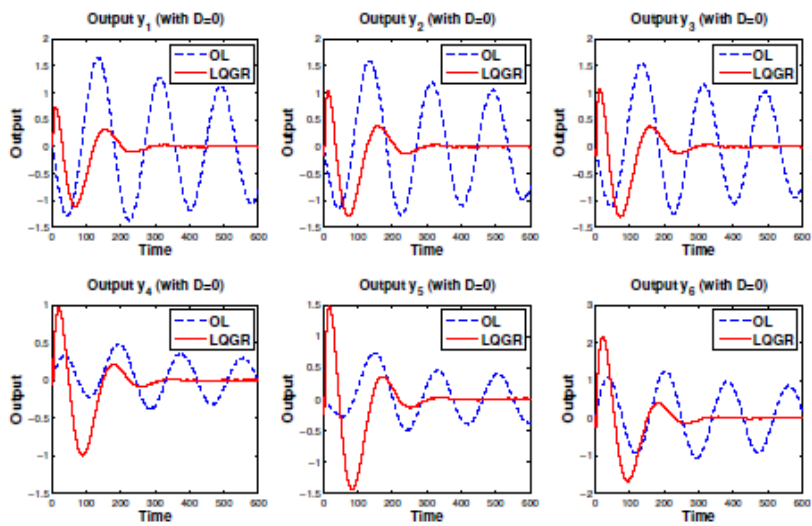

Fig 8. LQGR: Output trajectories for open loop and closed-loop systems
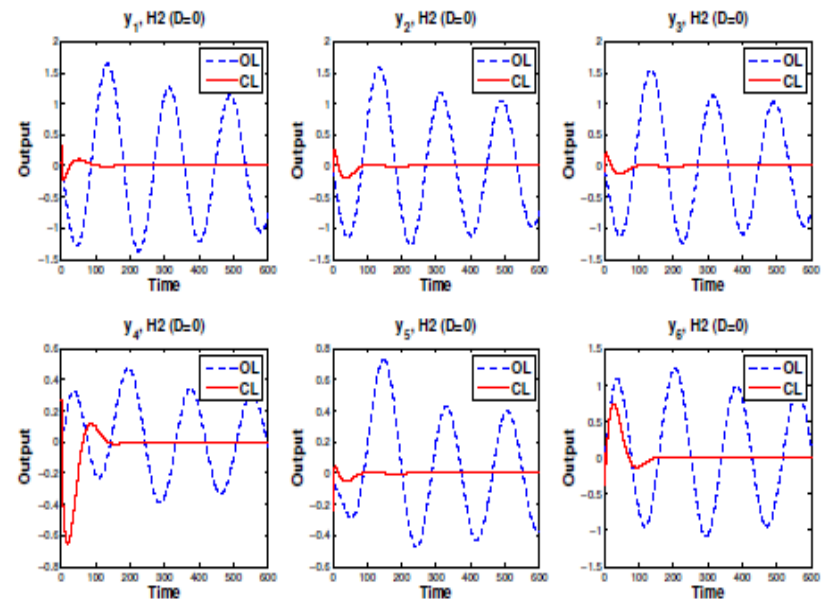

Fig 9. $\mathrm{H}_{2}$ : Output trajectories for open loop and closed-loop systems

\section{B. Adaptive Control Design}

Adaptive controller is a combination of control law (based on the known parameters) and online parameter estimation (through which unknown parameters are estimated at each instant) [5]. This online parameter estimator is known as adaptive law or update law, or adjustment mechanism. Based on this way of combining the control law and the adaptation law, the adaptive control is categorized into two types as direct adaptive control and indirect adaptive control.
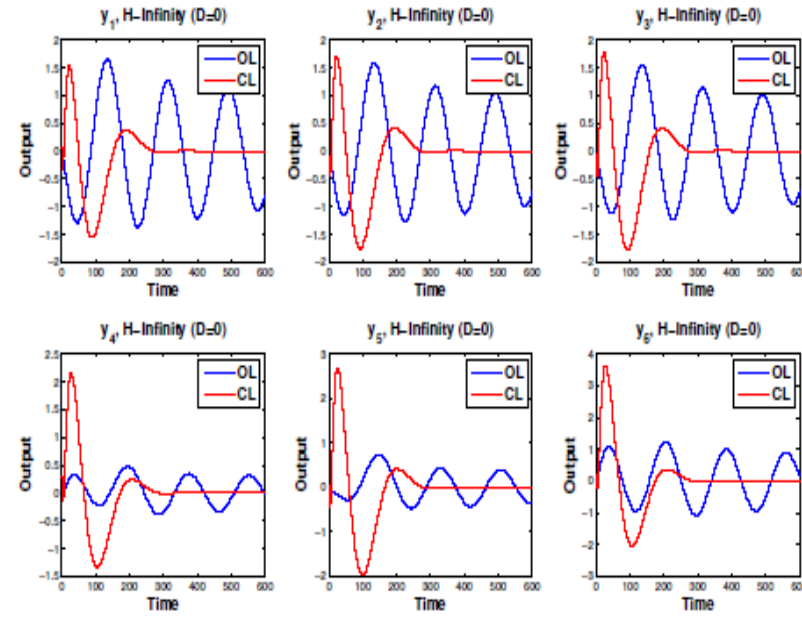

Fig 10. $\mathrm{H}_{\mathrm{oo}}$ : Output trajectories for open loop and closed-loop systems

In the sequel, we consider the direct model-reference adaptive control (MRAC), and the $\boldsymbol{L}_{1}$ adaptive control, shown in Figs. 11-12 and their implementation on the identified glass furnace model. We recall in MRAC that, the use of high adaptation gain results in high gain feedback control which further results in high-frequency oscillations in the control signal and reduced tolerance to time delays. Proper tuning (selection of appropriate adaptive gain) of MRAC is a difficult task. The $\boldsymbol{L}_{1}$ adaptive control method considers uniform performance bounds on the $\boldsymbol{L}_{1}$-norms of the errors in model states and control signals. As these error norms are (uniformly) inversely proportional to the square root of the adaptation gain, this method enables the use of high adaptation gains. The simulation is based on the theory in [5], [6]. The advantages of using the $\boldsymbol{L}_{1}$ adaptive controller is illustrated by comparing the simulation results of $\boldsymbol{L}_{1}$ adaptive control and MRAC.

The $\boldsymbol{L}_{1}$ adaptive control architecture consists of direct MRAC and a bandwidth-limited filter as shown in figure 12. The filter is used for the filtering of control signal in order to avoid high frequencies in the control signal and for shaping the nominal response. In adaptive control, though the increase in adaptation rate improves the tracking performance, it degrades the robustness of the controller. Hence, the adaptation rate is the key to tradeoff between performance and robustness. $\boldsymbol{L}_{1}$ adaptive control theory deals with this problem by setting up an architecture that separates the adaptation and robustness and thereby guarantees the transient performance and robustness in the presence of fast adaptation, without introducing or enforcing persistence of excitation, without any gain scheduling in the controller parameters, and without resorting to high-gain feedback [6].

The simulation results of L1 adaptive control are shown in Fig. 13 for the controlled output y2 for various bandwidths of the low-pass filter $\mathrm{C}(\mathrm{s})=\omega_{\mathrm{c}} / \mathrm{s}+\omega_{\mathrm{c}}$ of the $\boldsymbol{L}_{1}$ adaptive controller. The best response is obtained with a bandwidth 
Proc. of the Fourth Intl. Conf. Advances in Computing, Communication and Information Technology- CCIT 2016 Copyright $(\odot$ Institute of Research Engineers and Doctors, USA .All rights reserved.

ISBN: 978-1-63248-092-7 doi: 10.15224/ 978-1-63248-092-7-26

$\omega_{\mathrm{c}}=0.02 \mathrm{rad} / \mathrm{sec}$. From the plots shown in this figure, it is observed that for bandwidths higher than $\omega_{\mathrm{c}}=0.02 \mathrm{rad} / \mathrm{sec}$, as the bandwidth increases, the overshoot in the response of the system also increases and for bandwidths below this value the response is sluggish.

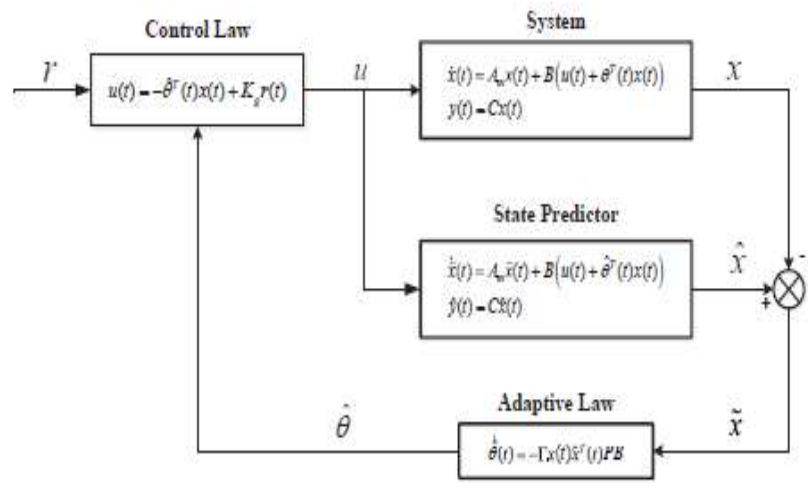

Fig 11. Direct MRAC with state predictor

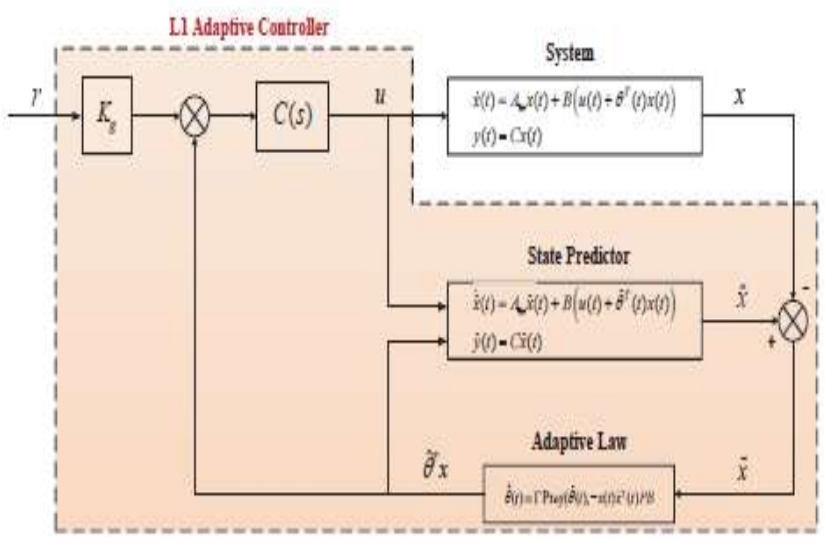

Fig 12. Closed-loop $\boldsymbol{L}_{1}$ adaptive system

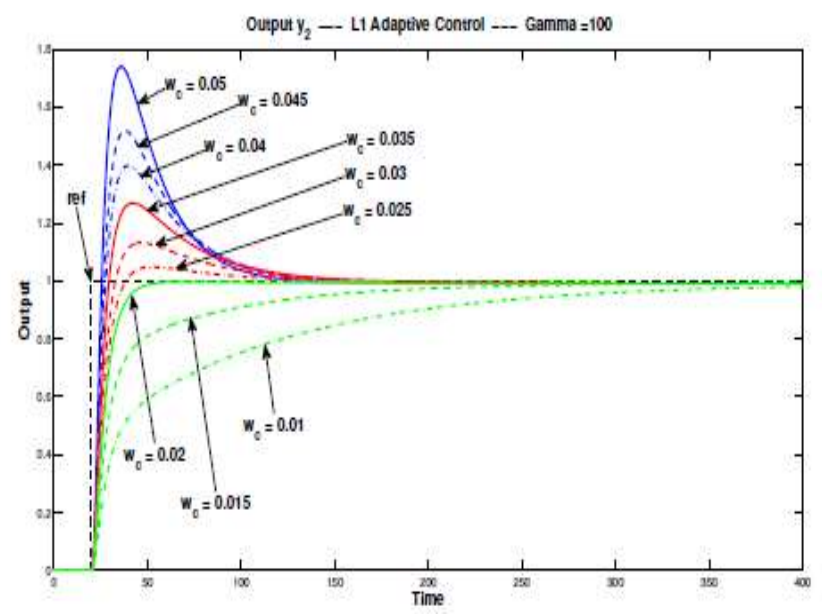

Fig 13. Output $y_{2}$ with $\boldsymbol{L}_{1}$ adaptive control at various filter bandwidths

Fig. 14 shows the plots of control inputs (unfiltered and filtered) of the $\boldsymbol{L}_{1}$ adaptive controller with the parameters $\omega_{c}$ $=0.02 \mathrm{rad} / \mathrm{sec}$, and $\Gamma=100$. A step input of magnitude of 1 unit is given as a reference signal. The output trajectories of this closed-loop system are presented in Fig. 15.

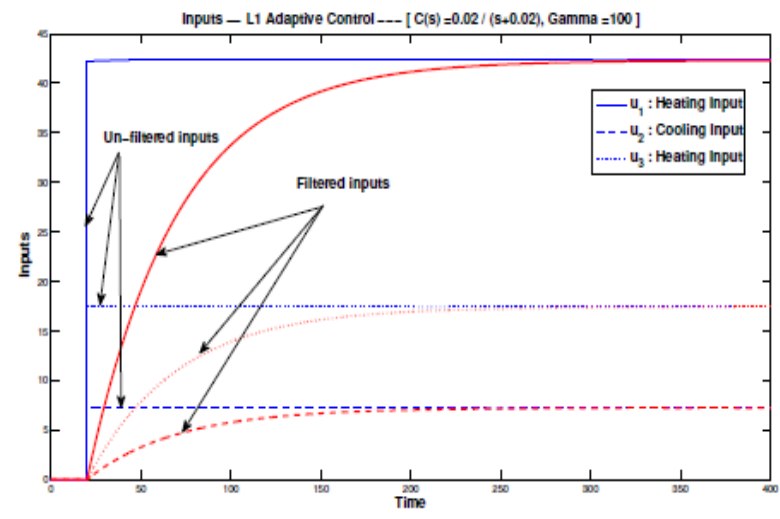

Fig $14 . \boldsymbol{L}_{1}$ adaptive system: control input trajectories

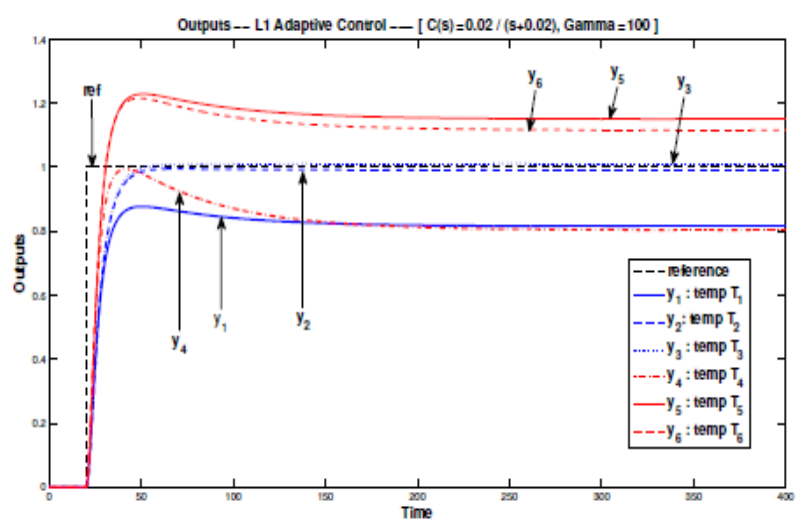

Fig $15 . \boldsymbol{L}_{1}$ adaptive system: output trajectories

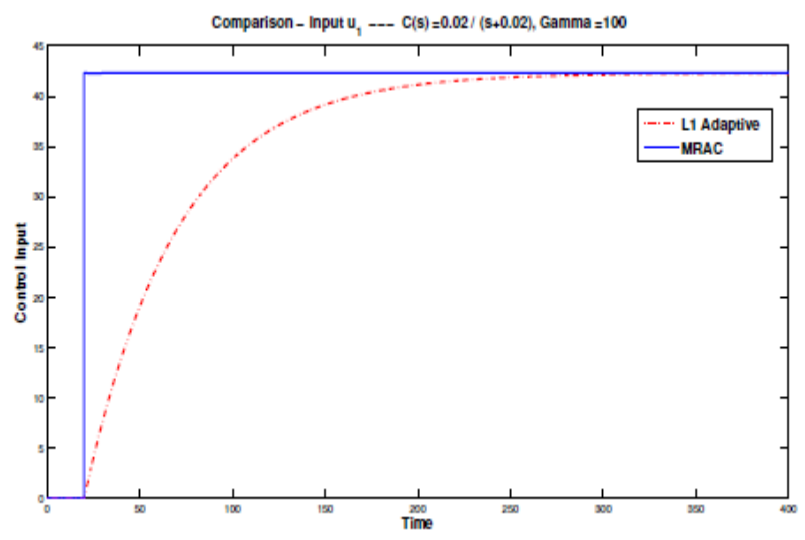

Fig 16. $\boldsymbol{L}_{1}$ adaptive vs MRAC: control input $\mathrm{u}_{1}$

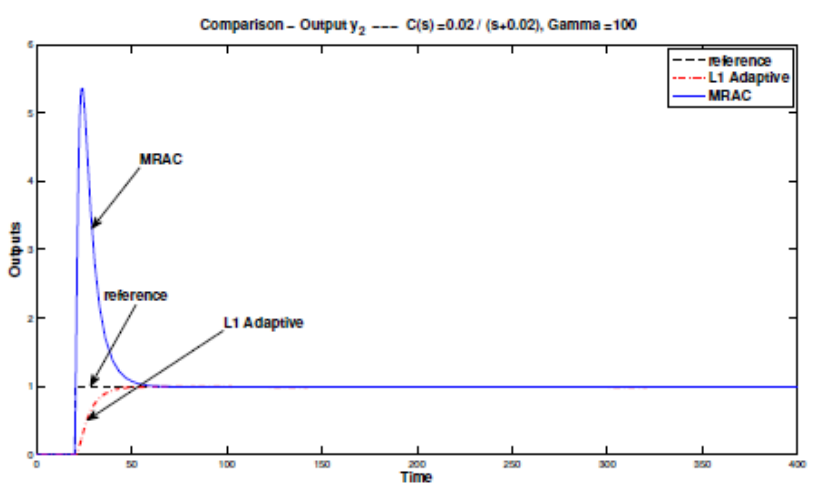

Fig 17. $\boldsymbol{L}_{1}$ adaptive vs MRAC: control input $\mathrm{u}_{2}$ 
Direct (MRAC) with state predictor has also been applied to this glass furnace model. The closed-loop responses of MRAC system and $\mathrm{L} 1$ adaptive system illustrated by control input $\mathrm{u}_{1}$ and output $\mathrm{y}_{2}$ in Figs. 16 and 17 respectively. It is seen that the system with $\boldsymbol{L}_{1}$ adaptive controller has a better transient response than the system with MRAC.

\section{Conclusions}

This paper has addressed a two-stage identification-control approach for a Philips glass furnace. Identification of the glass furnace system was performed using prediction error and N4SID methods. The estimated models were validated and their model fitness was compared. On comparison, it is found that the PEM model has the best fitness. The optimal and robust non-adaptive controllers (LQR. LQGR, $\mathrm{H}_{2}$ and $\mathrm{H}_{\mathrm{oo}}$ ) have been designed and applied to the identified glass furnace model. Implementing these controllers in closedloop with the glass furnace model resulted in satisfying results. In this regard, $\mathrm{H}_{2}$ controller has provided the best closed-loop performance. Model-reference adaptive control (MRAC) and $\boldsymbol{L}_{1}$ adaptive control methods were considered and it was found that the latter method has provided results with good transient response and good robustness characteristics.

\section{Acknowledgment}

The author would like to thank the deanship for scientific research (DSR) at KFUPM for research support through project no. RG 1316-1.

\section{References}

[1] D. Krause and H. L. (editors), "Mathematical simulation in glass technology", Glass and Glass Ceramics, Science, Technology and Applications, Springer-Verlag, 2009 pp. 17-73.

[2] T. C. Back, L. Huisman, P. Astrid, and R. Beerkens, "Model-based control of glass melting furnaces and forehearths: First principles-based model of predictive control system design," Proc. 63rd Conference on Glass Problems: Ceramic Engineering and Science, John Wiley \& Sons, Inc., 2008, pp. 21-47.

[3] A. Ponsich, C. Azzaro-Pantel, S. Domenech, L. Pibouleau, and F. Pigeonneau, "A systemic approach for glass manufacturing process modeling," Chemical Engineering and Processing: Process Intensification, vol. 48, pp. 1310-1320, 2009.

[4] V. Sardeshpande, U. N. Gaitonde, and R. Banerjee, "Model based energy benchmarking for glass furnace," Energy Conversion and Management, vol. 48, issue 10, pp. 2718-2738, 2007.

[5] C. Chengyu and N. Hovakimyan, "Design and Analysis of a Novel $\boldsymbol{L}_{1}$ Adaptive Controller, Part I: Control Signal and Asymptotic Stability," in American Control Conference, pp. 3397-3402, 2006.

[6] N. Hovakimyan and C. Cao, L1 Adaptive Control Theory: Guaranteed Robustness with Fast Adaptation: Society for Industrial and Applied Mathematics, 2010.

[7] P. Van Overschee and B. De Moor, "N4SID: Subspace algorithms for the identification of combined deterministic-stochastic systems," Automatica, vol. 30, pp. 75-93, 1994.

[8] H. Zhang, C. Z. Han, B. W. Wan, and R. Shi, "Identification and control of a large kinescope glass furnace," Automatica, vol. 30, pp. 887-892, 1994.

[9] L. Ljung, System Identification Toolbox - User's Guide (for use with MATLAB): The MathWorks, Inc, 1995.

[10] B. Gough, P. Eng, and D. Matovich, "Predictive-adaptive temperature control of molten glass," in Dynamic Modeling Control Applications for Industry Workshop, IEEE Industry Applications Society, pp. 51-55, 1997.

[11] Q. Wang, G. Chalaye, G. Thomas, and G. Gilles, "Predictive control of a glass process," Control Engineering Practice, vol. 5, pp. 167-173,
1997.

[12] O. Auchet, P. Riedinger, O. Malasse, and C. Iung, "First-principles simplified modeling of glass furnaces combustion chambers," Control Engineering Practice, vol. 16, pp. 1443-1456, 2008.

[13] E. Muysenberg and J. Chmelar, "Validation of glass furnace models: believe it or not," A Collection of Papers Presented at the 61st Conference on Glass Problems: Ceramic Engineering and Science, John Wiley \& Sons, Inc., pp. 1-19, 2008.

[14] W. Trier and K. L. Loewenstein, "Glass Furnaces: Design, Construction and Operation: Society of Glass Technology, 1987.

[15] G. S. Black, Jr., "Control technology applied to glass level regulation," Proc. IEEE Annual Meeting Industry Applications Society, vol.2, pp. 1111-1117, 1988

[16] J. Qi and G. Ma, "Design of glass furnace control system based on model-free adaptive controller," Proc. Second Int. Conference on Computer Modeling and Simulation, 2010, pp. 130-133.

[17] L. Huisman, "Estimation of process variables in a glass melting furnace," IFAC World Congress, Barcelona, Spain, 2002.

[18] P. van Santen, L. Huisman, and S. van Deelen, "Model-based process control for glass furnace operation," Proc. 71st Conference on Glass Problems, John Wiley \& Sons, Inc., 2011, pp. 203-213.

[19] S. Dequan, G. Guili, G. Zhiwei, and X. Peng, "Application of expert fuzzy PID method for temperature control of heating furnace," Procedia Engineering, vol. 29, pp. 257-261, 2012

[20] S. Liu and L. E. Banta, "Estimator-based LQR control model for glass fiber furnace," Int. J. Applied Glass Science, vol. 3, 2012, pp. $275-286$.

\section{About Author:}

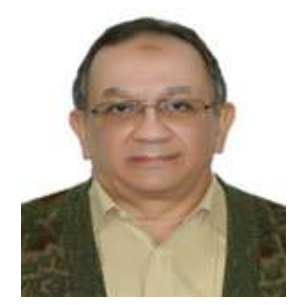

He has been a professor of engineering since 1984. He is now a Distinguished Professor at KFUPM, Saudi Arabia. He was on the faculty at different universities worldwide including Egypt (CU, AUC), Kuwait (KU), UAE (UAEU), UK (UMIST), USA (Pitt, Case Western), Singapore (Nanyang) and Australia (Adelaide). He lectured in Venezuela (Caracas), Germany (Hanover), UK ((Kent), USA (UoSA), Canada (Montreal) and China (BIT, Yanshan). He is the principal author of thirty-six (36) books, inclusive bookchapters and the author/co-author of more than $\mathbf{5 2 5}$ peerreviewed papers. He is the recipient of two national, one regional and several university prizes for outstanding research in engineering and applied mathematics. He is a fellow of the IEE, a senior member of the IEEE, the CEI (UK), and a registered consultant engineer of information engineering and systems (Egypt). He is a fellow of the IEE, a senior member of the IEEE, the CEI (UK), and a registered consultant engineer of information engineering and systems Egypt. 